\title{
El derecho a la igualdad, de Jaime Araújo Rentería, Presidente de la Honorable Corte Constitucional
}

Por ÁlVARO ECHEVERRY URUBURU*

Editado por la Corporación Universitaria Republicana y el Club de Abogados, Bogotá, s. f., $659 \mathrm{p}$.

Por honrosa e inmerecida distinción del doctor Jaime Araújo Rentería, me corresponde presentar, en el espacio académico proporcionado por esta joven Institución de Educación Superior, la Universidad Republicana, la obra de su autoría "El derecho a la igualdad".

Entre los grandes cambios suscitados por la Constitución de 1991, y gracias a la actividad constante y sin desmayos de pedagogía constitucional emprendida desde sus inicios por nuestro Tribunal Constitucional, se destaca, sin duda, una forma distinta de concebir y aplicar el derecho en nuestro medio; lo que algunos han denominado el "nuevo derecho". Sin introducirnos en el debate acerca de la validez o no del concepto; de la realidad hacia lo que el mismo apunta, un hecho resulta evidente: la renovación de la literatura jurídica con obras que se ocupan, ya no de manera general y sistemática de grandes conjuntos teóricos del derecho constitucional, sino de estudios específicos acerca de los más importantes principios y derechos consagrados en el texto político fundamental.

Este fenómeno, corriente ya en otras culturas jurídicas, como la alemana o española, hasta ahora comienza a cobrar vida en la nuestra, con obras pioneras como la del profesor Jaime Araújo, que rotura y abona el terreno para que muchos otros juristas continúen este trabajo intelectual de desentrañamiento, clarificación y sistematización del nuevo "corpus jurídico" nacional, surgido -así a muchos les pese- de la carta de 1991.

El principio de igualdad se encardina con los orígenes de un derecho democrático, que sin duda debemos al poderoso espíritu del mundo helénico.

El Derecho, designado con el término "dike", aludía en la Grecia clásica a una ley escrita igual para 
todos. Así como "themis" - el otro término para designar el derecho- se refería más bien a la autoridad del derecho, a su legalidad y validez, el de "dike" significaba la realización de la justicia.

Como lo ha sostenido Werner Jaeger, en una hermosa y célebre obra sobre la cultura Griega, la expresión "dike" "tenía una acepción más amplia y la hacía más adecuada para aquellas luchas -entre clases populares y aristócratas-: la significación de igualdad; de acuerdo a la idea popular de que era necesario pagar lo mismo con lo mismo, devolver lo mismo que se había recibido y dar compensación igual al daño recibido. Esta idea de igualdad es mantenida a lo largo de toda la historia griega, incluso a través del sentido mecanizado a que llegó el estado jurídico de la democracia y se opondría radicalmente a la doctrina aristocrática de Platón y Aristóteles sobre la desigualdad de los hombres (Jaeger, W., "Paideia", p. 108).

Allí también, en ese mundo griego del cual todos somos herederos en una o en otra forma -"todos somos griegos", diría el poeta Shilley- surge también la eterna antinomia que atraviesa siempre al derecho: la oposición entre la ley abstracta e imperativa, representada por "themis" y la justicia en concreto, como fuerza liberadora, encarnada en la "diké" y más tarde traducida por los romanos en la sonora expresión de "equitas" (equidad).

En su obra, el profesor Araújo justifica la trascendencia del tema, recordándonos como el $50 \%$ de las tutelas tramitadas en el país y el $60 \%$ de los cargos que se hacen por inconstitucionalidad de las leyes, involucra el principio -o como él lo considera- el derecho a la igualdad.

Las denominadas entre nosotros facultades de "modulación de las sentencias" -poderes auto atribuidos por la Corte Constitucional, que se desprenden de la necesidad de dar plena vigencia y materialidad al Estado social de derecho- y en particular, las llamadas por la doctrina Italiana "sentencias aditivas" que, en cumplimiento de principios y valores contenidos en la Constitución, incorpora a sectores o grupos de personas originalmente no previstas o arbitrariamente excluidas en la ley, son el resultado casi siempre de la aplicación del principio de igualdad, como muy bien lo explica el profesor Araújo al estudiar el fenómeno de "las omisiones del legislador" y en relación con estas, "la tipología de las sentencias de constitucionalidad".

Pero, si la ley puede violentar el principio de igualdad, discriminando o excluyendo, también pueden hacerlo los jueves en la producción de sus sentencias, incluso amparados en la propia ley que deben aplicar, pues ésta, a despecho de su postulación de igualdad formal, no trata a todo el mundo por igual. De aquí surge la solución anglosajona del precedente judicial, que pretende una aplicación uniforme de la ley a casos similares.

En este punto, el profesor Araújo introduce un importante tema de debate jurídico, al oponerse a quienes defienden la introducción de la institución del precedente judicial a nuestro sistema jurídico.

Independientemente de tratarse de la asunción acrítica de la ideología de la globalización, que para el caso del derecho sostiene la tesis de la convergencia de los sistemas continentales y los del "common law", el profesor Araújo proporciona una fuerte argumentación jurídica en contra de esta tendencia, al señalar, siguiendo a Kelsén, la diferencia entre normay sentido normativo, de suerte que una norma cualquiera puede tener varios sentidos normativos correctos de acuerdo con la Constitución. Lo cual, sin duda, conduce a que diversas intelecciones normativas comporten trato distinto de la ley a las personas por la vía de la libre interpretación judicial.

El profesor Araújo reivindica el derecho de los jueces a interpretar de manera distinta las normas, lo cual no constituye para él violación de la constitución y en particular del derecho a la igualdad. 
Con todo, la paradoja de sentencias contradictorias, aunque jurídicamente correctas, basadas en hechos similares y mediante la aplicación de las mismas normas, subsiste y no deja de provocar permanente desconcierto e inconformidad, coloreando la actividad de los juristas de un cierto halo de irracionalidad y arbitrariedad.

De ahí que, sin casarnos con la pretensión de introducir pura y simplemente el precedente judicial en nuestra cultura jurídica, si sería necesario insistir en la función unificadora y orientadora de la jurisprudencia producida por los tribunales de "cierre" de cada jurisdicción, de suerte que de ésta, los órganos y funcionarios inferiores de la rama judicial no pueden apartarse sin razones serias y valederas, claramente sustentadas mediante un sólido discurso argumentativo. Tal ha sido, a nuestro entender, la posición reiterada de la Corte Constitucional y que compartimos por considerar que la misma busca conferirle a la labor interpretativa judicial un mínimo grado de coherencia y racionalidad, como lo demanda una "sociedad bien organizada", para utilizar la terminología de Rawls.

Aunque la obra del profesor Araújo se ocupa en un primer momento del concepto de igualdad, para ofrecernos distintas definiciones de ésta a partir de la comprensión de su naturaleza relacional frente a cosas o personas, o de una posición empírica situacional que la entiende como "un punto de partida igual para todos", necesariamente se ve obligado a descender en los problemas de interpretación constitucional y en los distintos métodos de ésta, creados por la justicia constitucional a lo largo de casi cien años para el caso de la Corte Suprema americana y de cincuenta años para los tribunales constitucionales europeos.

A pesar del tiempo de existencia de la justicia constitucional en buena parte de las democracias contemporáneas, es necesario observar que la temática de la interpretación constitucional, "a nivel teórico y orgánico, es, aun cuando sorprenda, muy reciente y de no fácil aceptación -sostiene el jurista peruano Domingo García Belaunde-, a tal extremo que los constitucionalistas clásicos lo ignoran, y entre los actuales, son escasos los que le prestan atención" (García Belaunde, Domingo. “La interpretación constitucional como problema". En: Anuario de Derecho Constitucional Latinoamericano, Bogotá: Biblioteca Jurídica Dike, 1996, p. 48).

De ahí el mérito del trabajo del profesor Araújo, que aborda con rigor excepcional los grandes problemas metódicos de la interpretación constitucional.

Una de las técnicas más usuales del control constitucional contemporáneo lo constituye el "test de razonabilidad", creado por la jurisprudencia de la Corte Suprema norteamericana, particularmente para juzgar la pertinencia de aquellas medidas del legislador que tiendan a limitar o restringir derechos de las personas. Su categorización en test estricto, medio y leve, elaborada por dicha Corte $y$, particularmente, este último para analizar la constitucionalidad de las medidas sociales adoptadas durante el período del "New deal" del Presidente Roosevelt, es duramente criticado por el autor del libro que presentamos, considerando tal hecho como causa del debilitamiento del control constitucional en los Estados Unidos.

Independientemente de la validez o no que pueda tener la categorización creada por el tribunal norteamericano, conviene hacer algunas precisiones que tocan con el problema de los efectos de las sentencias de constitucionalidad y que surgen estimuladas por las opiniones polémicas vertidas por el doctor Araújo en su obra.

En primer término, el giro radical de la jurisprudencia de la Corte en 1937, al acoger la legislación social del Presidente Roosevelt, venía siendo preparada de tiempo atrás en virtud de los sucesivos salvamentos de voto sobre decisiones de aquella que tenían que ver con materias de contenido socio-económico producidas por jueces tan ilustres como Holmes y Brandais. 
En este sentido, las decisiones disidentes en las altas corporaciones judiciales, que nunca deben ser ni reservadas ni secretas, preparan y abren el camino a los grandes cambios en la jurisprudencia, que, con el tiempo y sin estos toques de alarma de las posiciones contrapuestas a las mayorías, tiende al estancamiento y a la esclerosis. Los votos en disidencia permiten ver las transformaciones en la jurisprudencia como el resultado natural de la evolución del pensamiento judicial y no como un fenómeno inopinado y hasta cierto punto caprichoso. En segundo término, ipodría una vieja posición doctrinal como lo era la "teoría de la libertad de contrato", a la cual se aferraba la Corte americana desde finales del siglo XIX, ser un factor de obstrucción de los profundos cambios sociales y económicos que demandaba la sociedad estaunidense para superar la "gran depresión" de los años 29-30 del siglo pasado? Máxime cuando aquella posición se basaba en una lectura sesgada de la Constitución de los Estados Unidos, que leía libertad de contrato donde solo decía libertad, como acertadamente lo criticaba el Magistrado Brandais en uno de sus célebres votos en disidencia.

Dos experiencias al menos cabe extraer de este período conflictivo de la historia americana con respecto al ejercicio del control constitucional en las sociedades democráticas:

1. La justicia constitucional debe evitar la tendencia al inmovilismo del texto constitucional. Por el contrario, debe mantenerlo vivo y actual por medio de una jurisprudencia creativa que sea capaz de captar los cambios que se producen en la vida social y las nuevas demandas sociales que aquellos generan. El dilema por tanto, que enfrenta siempre la justicia constitucional, es la de "ser valientemente creativa o completamente ineficaz", como lo expresa el gran jurista francés Jean Rivero.

2. La justicia constitucional no puede ser ajena a los resultados sociales, económicos y políticos de sus fallos. En este sentido, la labor de dicha justicia no es nunca neutral y aséptica, porque en la mayoría de los casos sus decisiones comprometen de manera significativa esferas completas de la vida Social. Por ello, se le impone una tarea de pronogsis, de avisoramiento de las consecuencias de sus fallos que incluso la pueden llevar a preferir el mantenimiento de una norma inconstitucional, sí con su declaratoria pudiesen afectarse severamente otros valores y principios constitucionales de mayor contenido axiológico.

Un tema que ha ocupado y dividido a la Corte americana durante los últimos veinte años, y estrechamente vinculado al principio de igualdad, es el relativo a la discriminación positiva, mejor denominada como lo hace el profesor Araújo, "acción afirmativa", que tiene que ver con aquellas políticas públicas orientadas a favorecer o privilegiar a grupos o sectores sociales -negros, indios, mujeres- que en el pasado sufrieron de discriminación o exclusión.

Para estos casos, la Corte Suprema ha utilizado un "test intermedio", más riguroso que el de la "razonabilidad", pero menos que el "examen exigente" o estricto, como lo llama el autor. Por su sofisticación este análisis ofrece algunos problemas: cada nivel de examen requiere que el Tribunal decida, de manera subjetiva, la importancia de la medida para los objetivos compensatorios con respecto a los grupos maltratados en el pasado, así como el grado de conveniencia de la clasificación que se hace de los beneficiados. El problema que ha enfrentado a la Corte durante estos años con respecto a la "acción afirmativa" tiene que ver con el interrogante de si los intentos del gobierno por compensara a determinados grupos por las carencias y sufrimientos del pasado, no viola el principio constitucional de "igual protección de la ley", en la medida en que resultan excluidos de determinadas políticas públicas individuos no pertenecientes a los grupos favorecidos (Cf. BARKER, Robert. "El 
control constitucional en los Estados Unidos de Norteamérica". En: Desafíos del control de constitucionalidad. Buenos Aires: Ediciones Ciudad Argentina, p. 312).

Del "test de racionabilidad" de la justicia norteamericana, el profesor Araújo pasa a ocuparse de otra técnica de valoración Constitucional, el juicio de proporcionabilidad utilizado por los Tribunales Europeos para juzgar aquellas normas que limitan o restringen derechos. Sobre el particular observa que en ocasiones nuestra Corte Constitucional ha confundido las dos técnicas, la del " test de racionabilidad" y la del "juicio de proporcionalidad" esto es, aplicando una gradualidad " leve" o " intermedia" a este último, cuando este no lo permite, ya que sus elementos constitutivos de licitud de la medida restrictiva, su adecuación a los propósitos pretendidos por la ley y sobre todo, su necesidad, esto es, que no exista otro medio menos gravoso para alcanzar los objetivos de la ley, deben darse "In integrum". De suerte que en el juicio de proporcionalidad no existe posibilidad de graduación, como si la existe en la técnica de razonabilidad norteamericana. Por ello, se advierte en la obra, al confundir las dos técnicas de valoración, nuestro Tribunal Constitucional le ha dado el pase de constitucionalidad a muchas normas claramente violatorias de derechos fundamentales.

Muchos son los temas de técnica constitucional de los cuales, con rigor y profundidad, se ocupa el profesor Araújo en la obra que presentamos y que harían interminable nuestra labor si quisiéramos abordarlos todos.

Sin embargo, para finalizar, quisiera referirme a una de sus tesis, contenida en alguna de sus aclaraciones de voto, que conforman la segunda parte del libro. Es la relativa a su oposición a la actual tesis mayoritaria de la Corte Constitucional, según la cual ésta no puede pronunciarse por vicios de procedimiento en la formación de la ley que el demandante no haya expresamente alegado. Posición tanto más peligrosa para el caso de actos reformativos de la Constitución, que tan sólo pueden ser acusados por vicios de procedimiento.

Esta posición de la Corte, que corrige la tesis contraria sostenida anteriormente, parece retrotraer la acción popular a épocas pretéritas en las que imperaban criterios casacionistas de estirpe civilista para la admisibilidad de las demandas de inexequibilidad, como aquel celebre principio elaborado por la Corte Suprema de Justicia, cuando fungía como Juez Constitucional, que obligaba al demandante a "integrar la proposición jurídica completa" o su doctrina sobre "la inepta demanda que provocaba el rechazo de la acción cuando el actor no expresaba de manera clara las razones de la violación". Compartimos pues las apreciaciones del profesor Araújo en este punto, pues toda exigencia formal, más allá de lo estrictamente razonable, vacía el contenido popular y democrático de la acción de inconstitucionalidad y configura una posición de autorrestricción inadmisible para quien posee la obligación de la defensa integral de la Constitución.

Reciba, doctor Araújo, en unión de los suyos, nuestras felicitaciones y las de la Facultad de Derecho de la Universidad Santo Tomás, que lo cuenta a usted como uno de sus más destacados y queridos profesores, por la culminación de este esfuerzo intelectual que ve coronado con la publicación de su obra. Ésta representa un paso más en su infatigable labor intelectual y lo coloca, como siempre lo ha estado, en el sitial de los grandes juristas del país, que engrandece con su saber, su rectitud y entereza de carácter, la actividad de nuestro máximo Tribunal Constitucional. 